\title{
ACF consists of two subunits, Acf 1 and ISWI, that function cooperatively in the ATP-dependent catalysis of chromatin assembly
}

\author{
Takashi Itoo, ${ }^{1-3}$ Mark E. Levenstein, ${ }^{1,3}$ Dmitry V. Fyodorov, ${ }^{1,3}$ Alan K. Kutach, ${ }^{1}$ Ryuji Kobayashi, ${ }^{4}$ \\ and James T. Kadonaga ${ }^{1,5}$ \\ ${ }^{1}$ Department of Biology and Center for Molecular Genetics, University of California, San Diego, La Jolla, California \\ 92093-0347 USA; ${ }^{4}$ Cold Spring Harbor Laboratory, Cold Spring Harbor, New York 11724 USA
}

The assembly of core histones and DNA into periodic nucleosome arrays is mediated by ACF, an ISWI-containing factor, and NAP-1, a core histone chaperone, in an ATP-dependent process. We describe the isolation of Drosophila acf1 cDNA, which encodes the p170 and p185 forms of the Acf1 protein in ACF. Acf1 is a novel protein that contains two PHD fingers, one bromodomain, and two new conserved regions. Human WSTF, which is encoded by one of multiple genes that is deleted in Williams syndrome individuals, is the only currently known mammalian protein with each of the conserved motifs in Acf1. Purification of the native form of Acf1 led to the isolation of ACF comprising Acf1 (both p170 and p185 forms) and ISWI. Native Acf1 did not copurify with components of NURF or CHRAC, which are other ISWI-containing complexes in Drosophila. Purified recombinant ACF, consisting of Acf1 (either p185 alone or both p170 and p185) and ISWI, catalyzes the deposition of histones into extended periodic nucleosome arrays. Notably, the Acf1 and ISWI subunits function synergistically in the assembly of chromatin. ISWI alone exhibits a weak activity that is $\sim 3 \%$ that of ACF. These results indicate that both Acf1 and ISWI participate in the chromatin assembly process and suggest further that the Acf1 subunit confers additional functionality to the general 'motor' activity of ISWI.

[Key Words: Chromatin assembly; ACF; Acf1; bromodomain; PHD finger; ISWI]

Received April 26, 1999; revised version accepted May 6, 1999.

Nucleosome assembly is a fundamental biological process that is required for the replication and maintenance of chromatin in the eukaryotic nucleus (for reviews, see Annunziato 1995; Wolfe 1995; Kaufman 1996; Roth and Allis 1996; Grunstein 1997; Ito et al. 1997a; Tsukiyama and Wu 1997; Wu 1997; Cairns 1998; Kadonaga 1998; Pollard and Peterson 1998; Workman and Kingston 1998; Adams and Kamakaka 1999; Kornberg and Lorch 1999). In dividing cells newly synthesized DNA is assembled rapidly into chromatin by a process that appears to involve an indirect coupling between DNA replication and nucleosome assembly. In quiescent cells, nucleosome assembly is required to replace histones that are lost in the course of histone turnover as well as to regenerate chromatin upon DNA repair. In addition, there may be a requirement for chromatin assembly during events, such

\footnotetext{
2Present address: Second Department of Biochemistry, Saitama Medical School, Moroyama, Iruma-gun, Saitama 350-0495 Japan.

${ }^{3}$ These authors made approximately equivalent contributions to this work.

${ }^{5}$ Corresponding author.

E-MAIL jkadonaga@ucsd.edu; FAX (619) 534-0555.
}

as transcription, that involves disruption of nucleosomes by the passage of polymerases.

Biochemical studies have led to the identification of proteins that are able to mediate the reconstitution of core histones into nucleosomes. Nearly all of these factors are core histone-binding proteins that contain stretches of acidic amino acid residues. Some of these histone chaperones, such as nucleoplasmin and nucleosome assembly protein-1 (NAP-1), exhibit a preference for binding to histones $\mathrm{H} 2 \mathrm{~A}$ and $\mathrm{H} 2 \mathrm{~B}$ relative to histones $\mathrm{H} 3$ and H4. Other histone chaperones, which include chromatin assembly factor 1 (CAF-1), N1/N2, and Spt6, associate preferentially with $\mathrm{H} 3$ and $\mathrm{H} 4$. Interestingly, it has also been observed that newly synthesized histones are acetylated (such as at positions 5, 8, and 12 of histone H4) and then subsequently deacetylated after assembly into chromatin. Thus, factors that mediate histone acetylation or deacetylation may participate, perhaps indirectly by the covalent modification of histones, in the chromatin assembly process.

These core histone chaperones can mediate the deposition of histones, to varying extents, onto DNA via an 
ATP-independent process that yields chromatin consisting of randomly distributed nucleosomes. This ATP-independent histone deposition process can also be carried out with salts, such as $2 \mathrm{M} \mathrm{NaCl}$, and polyanions, such as polyglutamate or RNA, which appear to interact with the histones and prevent their nonspecific aggregation with DNA. This random deposition process, however, is generally inefficient and does not yield periodic arrays of nucleosomes as is generally seen in native chromatin.

The assembly of regularly spaced nucleosome arrays is an ATP-dependent process, which was initially observed in an extract derived from Xenopus oocytes (Glikin et al. 1984). In studies of chromatin assembly factors from Drosophila embryos, the ATP-utilizing component of the chromatin assembly machinery, termed ACF (for ATP-utilizing chromatin assembly and remodeling factor), was identified and purified (Ito et al. 1997b). Purified ACF acts catalytically (at approximately one ACF protomer per 90 core histone octamers) in the deposition of histones to yield periodic nucleosome arrays in an ATP-dependent process. This chromatin assembly reaction, which can be carried out in a purified reconstituted system, requires $\mathrm{ACF}$, core histones, DNA, ATP, and a histone chaperone (NAP-1 and CAF-1 were each found to function as histone chaperones in conjunction with ACF). The most purified preparations of ACF were observed to consist of ISWI protein (Elfring et al. 1994) in addition to three other polypeptides. Western blot analysis of ISWI revealed that it copurified precisely with ACF activity through the final three purification steps; it was therefore concluded that ISWI is a component of ACF. The other three polypeptides of 47, 170 , and $185 \mathrm{kD}$ were assigned tentatively as subunits of ACF.

In this work we describe the isolation of the acf1 cDNA that encodes the 170- and 185-kD (p170 and p185) subunits of ACF. Purification of native Acf1 from Drosophila embryos led to the isolation of ACF consisting of Acf1 (both p170 and p185 forms) and ISWI subunits. Acf1 did not, however, copurify with components of NURF (Tsukiyama and Wu 1995; Tsukiyama et al. 1995) or CHRAC (Varga-Weisz et al. 1997), which are other chromatin remodeling complexes from Drosophila that similarly contain an ISWI subunit. Finally, studies of purified recombinant ACF revealed that the Acf1 and ISWI subunits function synergistically in the ATP-dependent assembly of nucleosome arrays. These findings should contribute to our understanding of the broad range of biological processes that involve assembly and remodeling of chromatin in the eukaryotic nucleus.

\section{Results and Discussion}

\section{Isolation of acf1 $c D N A$}

To gain a better understanding of the structure and function of ACF, we undertook the cloning of its putative subunits other than ISWI. To this end, we purified ACF from Drosophila embryos, subjected the p170 and p185 polypeptides to lysylendopeptidase digestion, purified p170 and p185 peptides by HPLC, and determined the partial amino acid sequences of several peptides. The HPLC elution profiles of the p170 and p185 lysylendopeptidase peptides suggested that the two proteins were related. In addition, one of the $\mathrm{p} 170$ peptides was found to have the same sequence as a p185 peptide. It therefore seemed likely that p170 and p185 were encoded by the same gene or related genes. By using RT-PCR techniques with oligonucleotides that corresponded to the predicted coding sequences of $\mathrm{p} 170 / \mathrm{p} 185$, we obtained a partial cDNA fragment that was used to screen a $\lambda$ phage cDNA library to yield acf1 cDNA, which encodes both p170 and p185, as described later in this work.

acf1 is a novel gene that encodes a protein of 1476 amino acid residues and has a calculated molecular mass of 170,350 daltons (Fig. 1A). Acf1 protein has two PHD finger motifs (Schindler et al. 1993; Aasland et al. 1995), one bromodomain (Haynes et al. 1992; Jeanmougin et al. 1997), and two novel conserved regions termed WAC (WSTF/Acf1/cbp146) and WAKZ (WSTF/Acf1/ KIAA0314/ZK783.4) motifs (Fig. 1B and 1C). The analysis of sequence databases revealed only one protein, human WSTF (Williams syndrome transcription factor; Lu et al. 1998), which possesses both WAC and WAKZ motifs as well as a PHD finger and a bromodomain at the carboxyl terminus. WSTF was identified previously as a gene that is deleted in Williams syndrome (WS) individuals (50 of 50 individuals tested; Lu et al. 1998). WS is a developmental disorder that results from hemizygous deletion of multiple contiguous genes at chromosome 7q11.23 (Morris et al. 1988; Bellugi et al. 1990; Ewart et al. 1993). WSTF was presumed to be a transcription factor because it contains a PHD finger and a bromodomain, but its biochemical function is not known. Given the structural relation between Acf1 and WSTF, it is possible that the analysis of ACF may provide information that is relevant to WS.

Other proteins possess either a WAC or a WAKZ motif. A WAC motif is present in mouse cbp146 (Tate et al. 1998) and in two Saccharomyces cerevisiae open reading frames, YGL133w (GenBank accession no. Z72655) and YPL216w (no. Z73572) (Fig. 1C). Unlike Acf1, neither YGL133w nor YPL216w proteins possess a WAKZ motif, a PHD finger, or a bromodomain. Because the cbp146 cDNA is incomplete, it is not known whether it shares other features of Acf1. A WAKZ motif is immediately amino-terminal to the first PHD finger of Acf1 and is also found in human cDNA KIAA0314 (Nagase et al. 1997) and Caenorhabditis elegans ZK783.4 (GenBank accession no. U13646) (Fig. 1C). KIAA0314 was identified in a screen for novel human cDNAs and encodes a protein of unknown function. It appears to be identical to TTF-I interacting peptide 5, which was found in a yeast two-hybrid screen for proteins that can bind to TTF-I (GenBank accession no. AF000422; also see Jansa et al. 1998). ZK783.4 (GenBank accession no. U13646) was identified in the $C$. elegans genome sequence. Notably, both KIAA0314 and ZK783.4 have one WAKZ mo- 


\section{A}

1 MPICKREGFD LNOKEGKNET FHDNDQVFCC YITKRIFRDY EHYFRHUMVI 51 NSTVWQCEAT GKENLTYEEA VKSERAARKK MEQFKQSLRA PVLLVVEHAO 101 QSAVIJINMI VAKFLLRRRYF IGEEVSVQAK KNATXTRLCV RLDKNMPEPL 151 NGIYEDTDNL VYRLRPNKGD PSAELDLPFR QLRRSRMEFN LENLSMFIKS 201 NUSRVDGLLR PKPEAYKOTV TMPGVMTSTI TIGKMPRYSP AKIKKPDGKK 251 OSTLNKYIVA GZATAAKSKA KAKSDAKSLA EELBRVKREK EAKLTXIMAKO 301 KAEKKAQLIE RVENECNLLL QKTDDLERTD QKVLPRYRQI VTLLPEHLLG 351 DAFMMREFMH TYTGLLSGIE VFRQNLSFYE MTRALTAREI AGPLSDILLY 401 LLGTVFDLQK EBEEECAYTY LDRAAQTQEP YWSMAQAAKS HLYAKRHFSE 451 KVNELPLDAL TLSEVLRLHL LGSGAFVNEK AERWRVMYRN GYSSKEDPGL 501 ELRLEHSHII RILKNHSWX LKEKDIMLII RCLMSQIMTY SGTINLIEER 551 MEQTAKARQD LRALVVGENK RLAAVEINRK KLTQNHHLEV NGVEPEKREA 601 LVEKLKKSIA ELHAQSDQQH RKHELQMLKL HSQLFNFLVY LGMDRCYRKY $65 I$ YVLESMPGIF VEHSPDSLET CLEQPITNKS OIEIRQQSAL PKNRKDLRVY 701 LLKLYGDDEK KTKEKAKHSI ENKENQEHRL NGSAEPMDVE SNSPEAPTHF 751 ELLMCSGDKR SCIVHDSRNG QRQRWAYIYK AEEIDELIFA LNPNGLREYE 801 LLQELSVLRS LIEQHAKTCP VDLLSLENET MRKKFMAAME SETNRKYGEA 851 NFGLPNGTDI, NEVMRLHLVD RIIQFENDIY TGDLGRLKVK DMEKWRSDLI 901 GGNYDAOCKL OWGPGGKLED EAGSDNESHE THEEDDGALL GKYARKPYRD 951 PGMYLAASAD TKRLPDSDDE EDQHTNAVLI PIAVHNMASA LLQVEQAIGK 1001 RFLKEPYGMK KWDPKQEALK IACDSRLHOW EVSLMESTSF AQVFLHLNIL 1051 HDCIOWRRST NKSLCKVCRR GSDPEKMLLC DECNAGTHMF CLKPKLRSVP 1101 PGNWYCNDCV KSLGLSHGQN EKDKKQATKK KRKFIVEEED DEATDEEEEE 1151 KKDDDMTDED AEHENEKHDE DVEDDESVTS TPSSSRVNGR ILRRPRTRFT 1201 SRRLTSKEIE BHAQEDVIDSG DVSDDASLTA GEDTIEDESD EEKVCQKCFY 1251 DGGEIKCVQC RLFFHLECVH LKRPPRTDFV CKTCKPMPQR PRRRHSNMNG 1301 DHDRDEEEEYK RKRPRNSLRL SIDKTARPSN GNNNNNNNNS SVNNNNHRRS 1351 GRRTNEHMPI NSAALYDLLE QIMKHKAAAP FLRPVLTSEV PDYHQIIKTP 1401 MDLAKIKSKI NMGAYQLNEE LLSDIQLVER NCDLYNVEGN EIYDAGCQLE 1451 RFVIDRCRDM QLPFRPSDMN GEVKAC

\section{$\mathrm{C}$}

\section{WAC Motif}

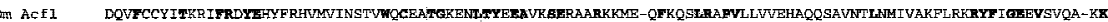

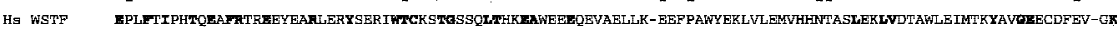

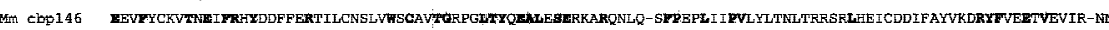
Sc YGL133W VQUWHIEZWGEWYSSYWEFLERFDFYTRHHFTCEITGTSCLTFFQALDSEETOFKYYEDRPPLXLREPYARFLHFNGI RRLDALYEKVYARFKNDFTPGEYYYLRK-QX

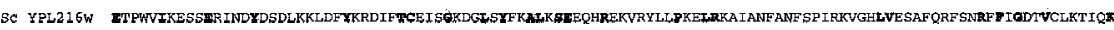

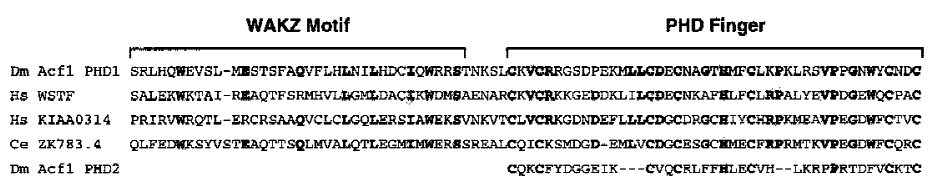

Bromodomain

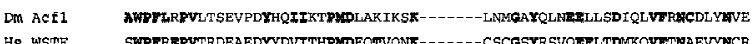

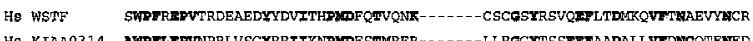

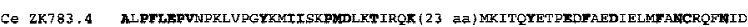

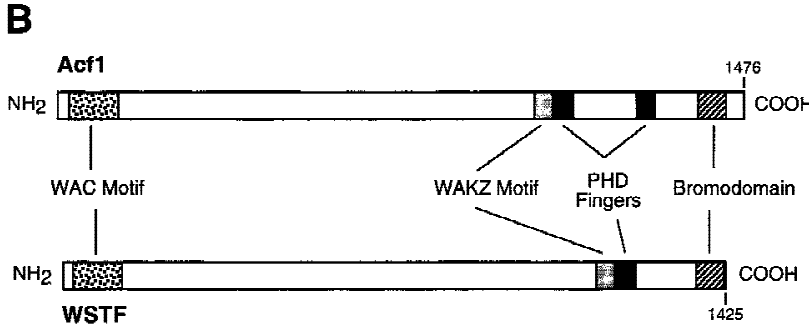

Figure 1. Sequence and features of Acf1 protein. (A) Predicted amino acid sequence of Acfl, as deduced from the cDNA sequence. The shaded regions indicate amino acid residues of native ACF that were determined by protein microsequencing. The acf1 cDNA sequence is in GenBank (accession no. AF148962). (B) Schematic diagram of Acf1. In addition to two PHD fingers (Schindler et al. 1993; Aasland et al. 1995) and a bromodomain (Haynes et al. 1992; Jeanmougin et al. 1997), Acf1 has two novel conserved regions termed WAC and WAKZ motifs. WSTF (Lu et al. 1998) is a human protein that appears to be related to Drosophila Acf1. (C) Alignment of sequence motifs in Acfl with some of their counterparts in other proteins. cbp146 was identified in a gene trap screen for chromoso$\mathrm{mal}$ and nuclear proteins in mice (Tate et al. 1998; CT146 cell line). YGL133w and YPL216w are from $S$. cerevisiae. KIAA0314 was identified in a screen for novel human cDNAs (Nagase et al. 1997) and appears to be identical to TTF-I-interacting peptide 5, which was identified in a yeast two-hybrid screen (also see Jansa et al. 1998). ZK783.4 is from C. elegans. tif, one PHD finger, and one bromodomain in an arrangement similar to that of Acf1 and WSTF. Also, the bromodomain motifs of Acf1, WSTF, KIAA0314, and ZK783.4 are closely related (Fig. 1C). Thus, it is possible that WSTF, KIAA0314, and ZK783.4 are subunits of factors that are related to ACF.

\section{Analysis of Acf1 at different stages of Drosophila development}

To determine whether or not the levels of Acf1 vary in the course of the growth and development of the organism, we carried out Western blot analyses of Acf1 throughout Drosophila development (Fig. 2). In these experiments we used affinity-purified antibodies against
Acf1, ISWI, and dNAP-1 in conjunction with approximately equivalent amounts of total protein derived from Drosophila at each of the indicated stages of development. Acf1 (both p170 and p185 forms) and ISWI were readily detected in embryos, but their levels were significantly lower in larvae, pupae, and adults. dNAP-1, on the other hand, was found to be present at high levels throughout development, except in adult males. With Acf1, it is also notable that there does not appear to be any significant variation in the relative amounts of the p170 versus p185 forms of the protein throughout embryogenesis. The presence of the highest levels of Acf1 and ISWI in embryos roughly correlates with the high amounts of DNA replication and chromatin assembly as well as transcription and chromatin remodeling that occurs during embryogenesis. 


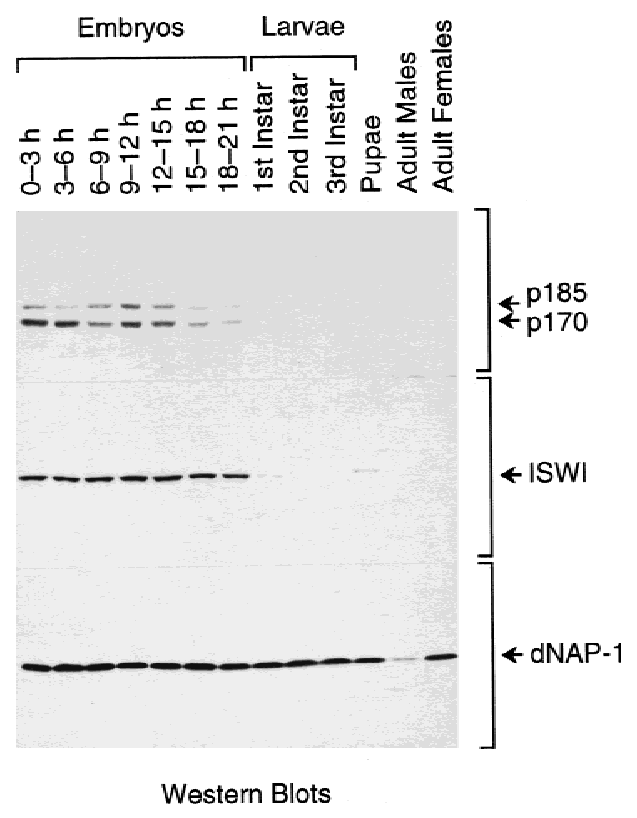

Figure 2. Western blot analysis of Acf1 at different stages of Drosophila development. Equivalent amounts of total soluble protein derived from Drosophila at the indicated stages of development were subjected to polyacrylamide-SDS gel electrophoresis and Western blot analysis.

The majority of Acf1 is associated with ISWI in the ACF complex

To determine whether the majority of Acf1 exists in the ACF complex, we purified the native form of Acf1 from Drosophila embryos by using a Western blot assay with antibodies against Acf1. The scheme for the purification of native Acf1 is outlined in Fig. 3A.

In these experiments, we additionally investigated the relation between Acf1 and two other Drosophila ISWIcontaining complexes, nucleosome remodeling factor (NURF) and chromatin-assembly complex (CHRAC). NURF consists of ISWI (Tsukiyama et al. 1995), NURF55 (Martínez-Balbás et al. 1998) (NURF-55 is identical to dCAF-1 p55; Tyler et al. 1996), inorganic pyrophosphatase (Gdula et al. 1998), and a $215-\mathrm{kD}$ subunit. CHRAC is a complex of $670 \mathrm{kD}$ native mass (as determined by gel filtration) that contains ISWI, topoisomerase II, and proteins with apparent molecular masses of $\sim 175,20$, and 18 $\mathrm{kD}$ (Varga-Weisz et al. 1997). Therefore, in the course of the purification of native Acf1, we simultaneously carried out Western blot assays for Acf1 and ISWI as well as for dCAF-1 p55/NURF-55 and topoisomerase II to test for the potential copurification of Acfl with NURF or CHRAC.

Western blot analyses of protein fractions from the last three purification steps are shown in Figure 3. During gradient elution of the hydroxyapatite resin, Acf1 (p170p185) and ISWI were found to coelute at a lower potassium phosphate concentration than topoisomerase II or dCAF-1 p55/NURF-55 (Fig. 3B). The peak hydroxyapatite fractions were then applied to a POROS heparin resin. In POROS heparin chromatography, Acf1 (p170p185) and ISWI were observed to coelute at a distinct $\mathrm{NaCl}$ concentration from dCAF-1 p55/NURF-55, whereas the amount of topoisomerase II in Acf1-containing fractions decreased below levels that could be detected (Fig. 3C). Finally, the peak POROS heparin fractions were purified by glycerol gradient sedimentation, and Acf1 (p170-p185) was observed to cosediment with ISWI but not with dCAF-1 p55/NURF-55 (Fig. 3D).

The chromatin assembly activity of the protein fractions was also determined in a standard ACF assay in conjunction with micrococcal nuclease digestion analysis (Ito et al. 1997b; also see Materials and Methods). ACF chromatin assembly activity comigrated precisely with Acf1 protein through the last three purification steps, and the results with glycerol gradient sedimentation are shown in Figure 3E.

Analysis of the protein composition of the most purified Acf1-containing fractions by SDS-PAGE and silver staining revealed that Acf1 (p170 and p185) and ISWI were the only polypeptides that comigrate with ACF activity (Fig. 3F, fractions 7-9). Notably, the p47 polypeptide that was seen previously in ACF preparations (Ito et al. 1997b) was not detected. Consistent with this observation, partial amino acid sequence of $\mathrm{p} 47$ was determined (the sequences obtained were NPQSGNRSGRRSNSLDNVEQ and LYHLSQFNHVFKPDYTPEPSQIRG) and found to be identical to Drosophila yolk protein 2 (Hung and Wensink 1983). Thus, p47 appears to have been a contaminant in the earlier ACF preparations.

These results show that the purification of the native form of Acf1 leads to the isolation of the ACF complex that comprises Acf1 (p170 and p185) and ISWI. Given that the ACF complex exhibits an apparent molecular mass of $220 \mathrm{kD}$ by glycerol gradient sedimentation (Ito et al. 1997b) and the calculated molecular masses of Acf1 and ISWI are 170 and $119 \mathrm{kD}$, respectively, it appears likely that an ACF protomer consists of heterodimers of either p170 + ISWI or p185 + ISWI.

These studies also suggest that the majority of Acf1 appears to exist as a subunit of ACF. It is therefore possible that Acfl is a unique component of ACF, but it cannot be excluded that Acf1 may be present in other less abundant forms. Finally, the distinct purification properties of dCAF-1 p55/NURF-55 and topoisomerase II (a component of CHRAC) relative to ACF, as detected by Western blot analyses (Fig. 3B-D) and SDS-PAGE (Fig. $3 \mathrm{~F}$ ), support the conclusion that ACF is distinct from NURF and CHRAC.

\section{Purified recombinant ACF comprising Acf1 and ISWI is active for chromatin assembly}

Because native ACF appears to consist of Acf1 and ISWI, we undertook the synthesis and purification of the recombinant proteins. To this end, we constructed baculovirus expression vectors for full-length Acf1 protein as well as for full-length Acf1 with a carboxy-terminal Flag (Sigma) epitope tag (termed Acf1-Flag). A baculovirus vector that produces amino-terminally Flag-tagged Dro- 
A

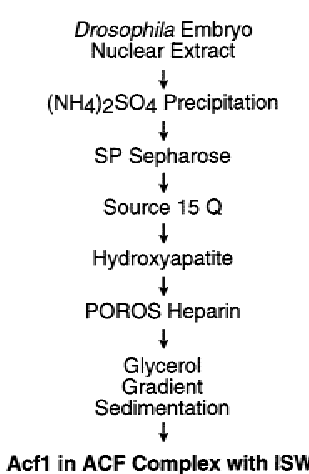

Acf1 in ACF Complex with ISWI

C

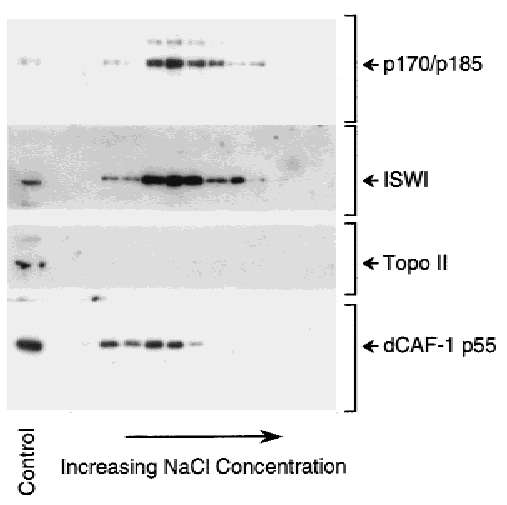

E

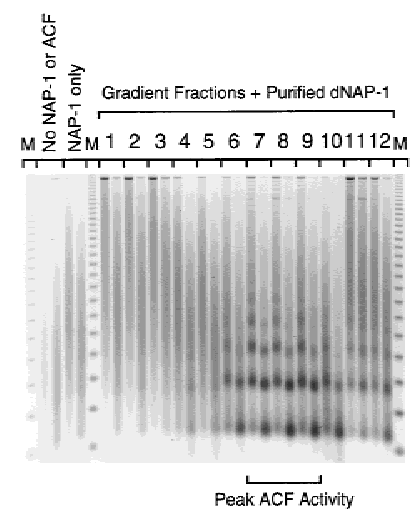

Micrococcal Nuclease Digestion Analysis
B

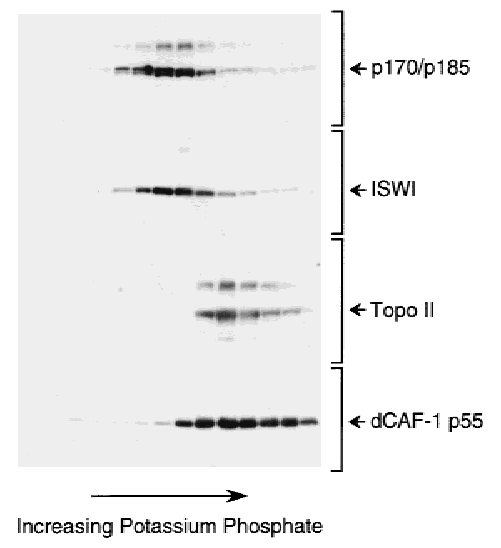

D

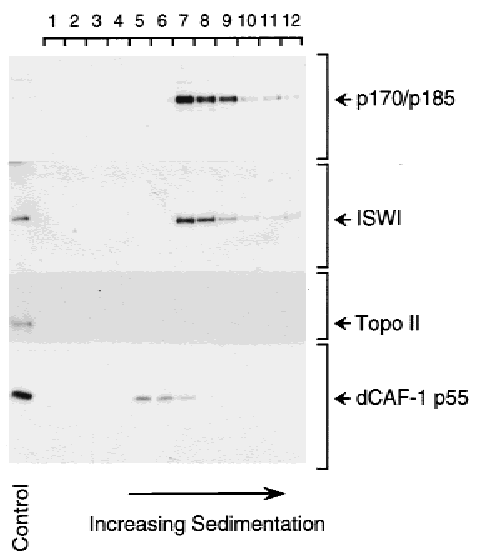

$\mathbf{F}$

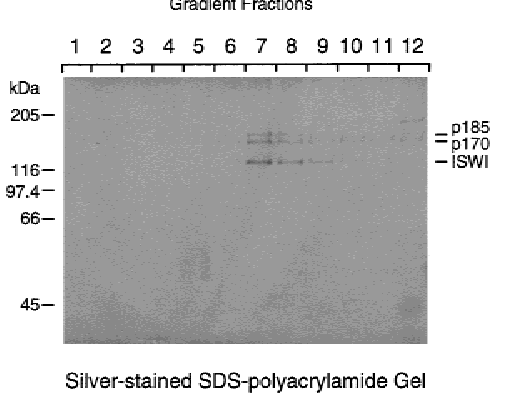

Figure 3. Purification of the native form of Acf1 leads to the isolation of ACF comprising Acf1 (p170 and p185) and ISWI. (A) Scheme for the purification of native form of Acf1 from Drosophila embryos. (B) Hydroxyapatite chromatography. The peak gradient fractions from the Source 15Q (Pharmacia Biotech) column were applied to a BioGel HT hydroxyapatite (Bio-Rad) column, and protein was eluted with a linear potassium phosphate gradient. The column fractions were subjected to Western blot analysis with antibodies against Drosophila Acf1 (p170/p185), ISWI, topoisomerase II, and dCAF-1 p55 in conjunction with ${ }^{125}$ I-labeled protein A. With the Acf1 Western blot, the p170 and p185 forms of Acf1 were not clearly resolved. Also, the slower migrating species that cross-reacts with the Acf1 antiserum is not recognized by the affinity-purified antibodies (e.g., see Fig. 2). (C) POROS heparin chromatography. The peak hydroxyapatite fractions were applied to a POROS heparin (PerSeptive Biosystems) column, and protein was eluted with a linear $\mathrm{NaCl}$ gradient. The column fractions were subjected to Western blot analysis, as in $B$. The control sample is an ACF-containing fraction from the Source 15Q chromatography step. The p170 and p185 forms of Acf1 were not clearly resolved. $(D)$ Glycerol gradient sedimentation. The peak POROS heparin fractions were subjected to $15 \%$ $40 \%$ (vol/vol) glycerol gradient sedimentation. The glycerol gradient fractions were subjected to Western blot analysis, as in $B$ and $C$. The p170 and p185 forms of Acf1 were not clearly resolved. $(E)$ Micrococcal nuclease digestion analysis. ACF activity in the glycerol gradient fractions was tested by micrococcal nuclease digestion analysis. Chromatin assembly reactions contained $10 \mu \mathrm{l}$ of each $400 \mu \mathrm{l}$ fraction and were carried out as described in Materials and Methods. The samples were then partially digested with two different concentrations of micrococcal nuclease. The resulting DNA fragments were deproteinized, resolved by $1.5 \%$ agarose gel electrophoresis, and visualized by staining with ethidium bromide. The mass markers $(\mathrm{M})$ are the 123-bp DNA ladder (GIBCO-BRL). The peak of ACF activity is seen in fractions 7-9. (F) Native ACF consists of Acf1 (p185 and p170) and ISWI. Glycerol gradient fractions were subjected to $6 \%$ polyacrylamide-SDS gel electrophoresis, and proteins were visualized by silver staining. The sizes of molecular mass markers and the ACF subunits are indicated. The traces of dCAF-1 p55/NURF-55 that were seen in Western blots of the glycerol gradient fractions $(D)$ could not be detected in these silver-stained SDS-polyacrylamide gels.

sophila ISWI (Flag-ISWI) (Corona et al. 1999) was kindly provided by Dr. C. Wu (National Institutes of Health, Bethesda, MD). Acf1-Flag and Flag-ISWI were individually synthesized and purified (Fig. 4A). In addition, an ACF complex comprising both Acfl and ISWI was obtained by cosynthesis (i.e., coinfection of the corresponding recombinant baculoviruses) of Acf1 and Flag-ISWI followed by affinity purification via the Flag epitope tag to yield ACF consisting of both Acf1 and Flag-ISWI (Fig. 4A).

Interestingly, both the p170 and p185 forms of Acf 1 can be derived from the acf1 cDNA. When Acf1-Flag is affinity-purified via its carboxy-terminal Flag tag, only the p185 form of Acf1 was seen (Fig. 4A), even when a 
Figure 4. Chromatin assembly by purified recombinant Acf1 and ISWI. (A) Purification of recombinant Acf1 and ISWI. Acf1Flag alone, Flag-ISWI alone, or Acf1 + Flag-ISWI together were synthesized with a baculovirus expression system and then purified by using the Flag affinity tag. The proteins (185 $\mathrm{ng}$ of Acf1-Flag or Acf1; 140 ng of Flag-ISWI) were analyzed by $6 \%$ polyacrylamide-SDS gel electrophoresis and silver staining. The polypeptide that migrates below Flag-ISWI in the cosynthesized Acf1 + Flag-ISWI preparation is an unknown contaminant. (B) Both p170 and p185 are synthesized from the acf1 cDNA. Native ACF (after hydroxyapatite chromatography, as shown in Fig. 3B) and recombinant ACF, which was obtained by cosynthesis of Acf1 and Flag-ISWI and purification with the Flag epitope tag, were subjected to $6 \%$ polyacrylamide-SDS gel electrophoresis and Western blot analysis with affinity-purified antibodies that recognize the TYE peptide of Acf1 (described in Materials and Methods). (C) Recombinant ACF can function catalytically in the assembly of chromatin. Chromatin assembly and micrococcal nuclease digestion assays were performed with varying concentrations of purified, recombinant ACF (rACF). The resulting DNA samples were resolved by $1.2 \%$ agarose gel electrophoresis and detected by staining with ethidium bromide. One unit of ACF is defined to be 22 fmoles, which corresponds to one ACF protomer per 150 core histone octamers in this assay. $(D)$ DNA supercoiling analysis of chromatin assembly by recombinant ACF. Standard chromatin assembly reactions were carried out in the presence or absence of purified recombinant ACF (rACF, $10 \mathrm{U} /$ reaction) with recombinant dNAP-1 and purified Drosophila core histones. The assembly reactions were terminated at the indicated time points by the addition of EDTA to $50 \mathrm{~mm}$ final concentration. The samples were then deproteinized and subjected to $1.0 \%$ agarose gel electrophoresis. The DNA was detected by staining with ethidium bromide.

large excess of protein is analyzed by gel electrophoresis (data not shown). In contrast, both the p185 and p170 forms of Acf1 copurify with Flag-ISWI. In the silverstained gel shown in Fig. 4A, the p185 band can be seen clearly, and the p170 band is faint yet detectable. Western blot analyses with anti-Acf1 antibodies reveal the presence of the recombinant p170 band more distinctly (Fig. 4B). These data suggest that both $\mathrm{p} 170$ and $\mathrm{p} 185$ are produced from the acf1 cDNA, but the structural relation between the p170 and p185 forms is not known.

To determine whether the recombinant proteins can function in the assembly of nucleosome arrays, we carried out chromatin assembly reactions with purified core histones, purified dNAP-1, relaxed circular plasmid DNA, and ATP (with an ATP regenerating system) along with varying concentrations of purified recombinant ACF (cosynthesized Acf1 + Flag-ISWI) (Fig. 4C). These experiments revealed significant chromatin assembly activity at a core histone octamer/ACF molar ratio of 150:1 (1 unit), and an optimal chromatin assembly activity can be achieved at an octamer/ACF molar ratio of 50:1 (3 units). The ability of recombinant ACF to catalyze the assembly of nucleosome arrays at an octamer/ACF ratio of $\sim 50: 1$ to $150: 1$ is consistent with the previously observed ability of native ACF to assemble chromatin at an estimated octamer/ACF ratio of 90:1 (Ito et al. 1997b).

At a high level of recombinant ACF (100 units), which
A

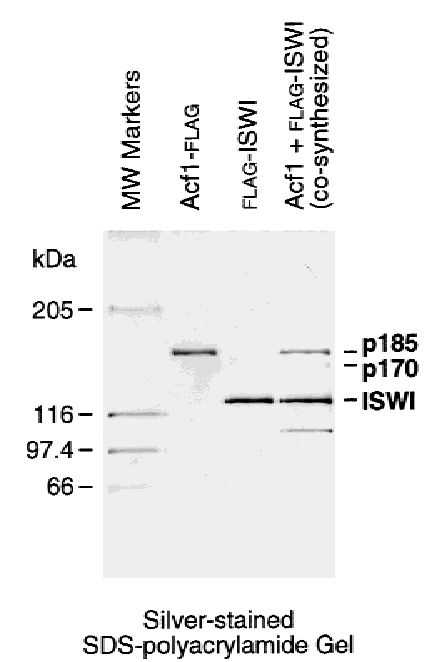

B

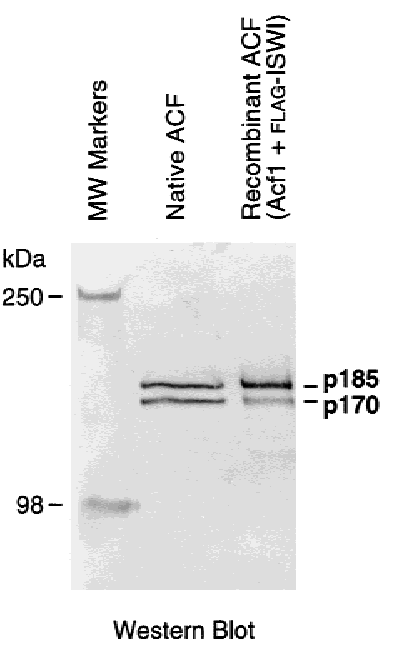

C

rACF $\begin{array}{llllll}0 & 1 & 3 & 10 & 30 & 100 \\ \text { units }\end{array}$

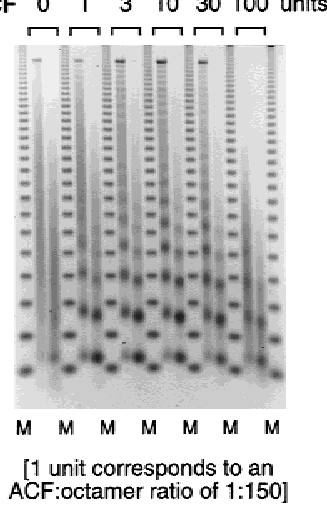

D

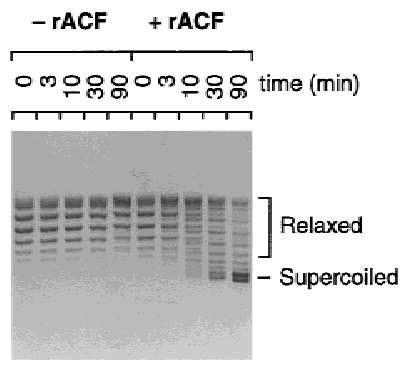

DNA Supercoiling Assay

corresponds to nearly one ( 0.67) ACF per nucleosome, a periodic nucleosome array is not obtained (Fig. 4C). It is possible that this high concentration of ACF destabilizes chromatin, perhaps by hyperactive remodeling activity or by binding of the excess ACF to DNA or to nucleosomes. Alternatively, it is possible that a minor contaminating species in the ACF preparation (which is being used at $\sim 30$ times the concentration that is needed for full chromatin assembly) is causing degradation or destabilization of DNA or chromatin. Given the high concentrations of ACF that are needed to observe this effect, it seems unlikely to reflect the normal function of ACF.

An important feature of ACF is its ability to facilitate the deposition of histones onto DNA (Ito et al. 1997b). We therefore analyzed the ability of recombinant ACF to catalyze the formation of nucleosomes by using the DNA supercoiling assay (Fig. 4D). As seen previously (Bulger et al. 1995; Ito et al. 1996; in earlier studies, dNAP-1 had been termed p56/dCAF- 4 and the dCAF-1 fraction contained $\mathrm{ACF}$ ), there is inefficient deposition of histones by purified dNAP-1 in the absence of ACF. Then, upon addition of ACF, there is a significant increase in the extent of nucleosome assembly. Thus, re- 
combinant ACF functions as a nucleosome assembly factor that facilitates the deposition of histones onto DNA by a process that yields periodic nucleosome arrays. Hence, the recombinant ACF, which comprises Acf 1 and ISWI, possesses chromatin assembly activity that is comparable to that of native ACF.

Because the bromodomain has been found in proteins that exhibit histone acetyltransferase activity, we also tested whether Acf1, which has a carboxy-terminal bromodomain (Fig. 1), is able to mediate the acetylation of histones in the presence of acetyl-CoA. These experiments revealed that purified recombinant Acf1 alone or ACF (Acf1 + ISWI) each exhibited approximately 1\%-2\% (on a molar basis) of the acetyltransferase activity of purified human p300 (data not shown). Hence, these results indicate that neither Acf1 alone nor ACF possesses significant histone acetyltransferase activity.

\section{Acf1 functions synergistically with ISWI in nucleosome assembly}

To investigate the role of Acf1 in nucleosome assembly by ACF, we carried out standard chromatin assembly reactions with recombinant Acf1 alone, ISWI alone, or ACF (Fig. 5A). These experiments revealed no detectable chromatin assembly with 10 units of either Acf1 alone (Fig. 5A, cf. lanes 1 and 2) or ISWI alone (Fig. 5A, cf. lanes 1 and 4). In contrast, chromatin assembly activity was seen with 1 or 10 units of ACF (Fig. 5A, lanes 6,7) and was dependent on the presence of ATP (Fig. 5A, cf. lanes 7 and 8). The finding that 1 unit of ACF yields greater chromatin assembly activity than 10 units of either subunit alone indicates that the Acf1 and ISWI subunits of ACF function cooperatively in the assembly of periodic nucleosome arrays.

We also tested the chromatin assembly activity of high levels (100 units) of the individual subunits and observed slight activity with Acf1 alone (Fig. 5A, lane 3) and strong activity with ISWI alone (Fig. 5A, lane 5). From these and other related experiments (Fig. 4C; data not shown), we estimate that ACF assembles chromatin $~ 30$ fold more efficiently than ISWI alone. The results with ISWI alone are in accord with the observation that bacterially synthesized ISWI can mediate the formation of a stretch of nucleosomes (up to four bands in the micrococcal nuclease digestion assay) at an octamer/ISWI ratio of about 2.7:1 under similar conditions (Corona et al. 1999). With baculovirus-synthesized ISWI (at an octamer/ISWI ratio of $\sim 1.5: 1$ ), however, we observe a more extensive nucleosome array (seven distinct bands in the micrococcal nuclease assay; Fig. 5A, lane 5) than that seen with the bacterially synthesized ISWI (Corona et al. 1999|. It should also be noted that some of the activity in our preparation of baculovirus-synthesized ISWI could be due to a low level of contaminating endogenous Spodoptera frugiperda Acf1 from the Sf9 cells that may copurify with the recombinant Flag-ISWI. [On the other hand, the barely detectable level of nucleosome spacing activity with high levels of Acf1 alone (which exhibited $<0.5 \%$ of the activity of ACF; Fig. 5A, lane 3) did not

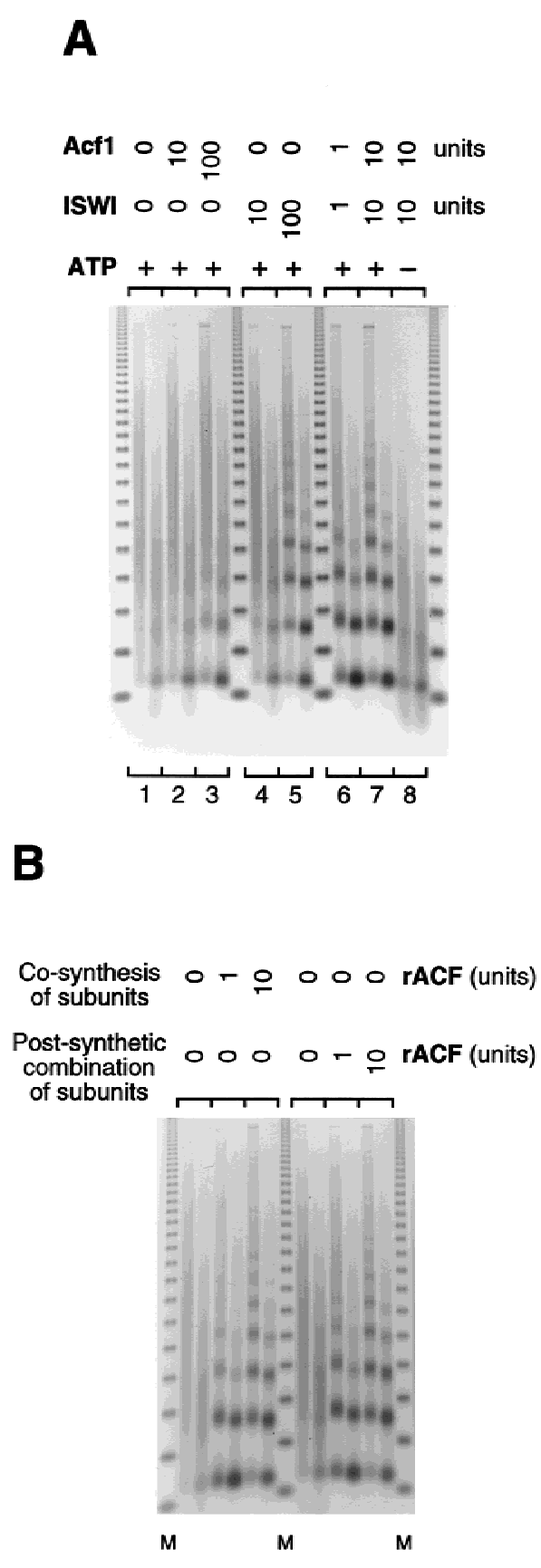

Figure 5. Acf1 and ISWI function cooperatively in the catalysis of chromatin assembly. (A) Chromatin assembly reactions were carried out with the indicated amounts of individual recombinant ACF subunits (Acf1-Flag or Flag-ISWI) or ACF (cosynthesized Acf1 + Flag-ISWI). In addition, where noted, ATP was not included in the reaction with ACF. These and other related experiments (see, e.g., Fig. 4C) indicate that ACF assembles chromatin $\sim 30$-fold more efficiently than either subunit alone. One unit corresponds to 22 fmoles of protein. (B) Acf1 and ISWI can be combined postsynthetically to yield active ACF. Chromatin was assembled with either cosynthesized Acf1 + FlagISWI [which consists of p185, p170, and ISWI, as seen in Fig. 4A] or individual Acf1-Flag [which consists of p185 only, as shown in Fig. 4A] and Flag-ISWI polypeptides that had been combined after purification (postsynthetic combination of subunits). One unit corresponds to 22 fmoles of protein. 
appear to be ATP-dependent (data not shown); thus, it seems unlikely that it was due to contaminating $S$. frugiperda ISWI from Sf9 cells.] Nevertheless, the collective data are generally consistent and indicate that ISWI alone has a weak chromatin assembly activity that is $\leq 3 \%$ of the activity of ACF.

Because the Acfl and ISWI subunits are both required for full ACF activity, we tested whether purified preparations of the separate subunits could be combined to yield active ACF (Fig. 5B). We carried out chromatin assembly reactions with Acf1-Flag and Flag-ISWI that had been combined after synthesis and purification (postsynthetic) as well as with Acf1 + Flag-ISWI that had been cosynthesized and purified as the ACF complex (cosynthesis). As seen in Figure 5B, the activity of the postsynthetically combined ACF subunits is essentially identical to that of the cosynthesized subunits. Therefore, cosynthesis of the Acfl and ISWI subunits is not necessary to obtain fully active ACF. In addition, because the p170 form of Acf is not present in the purified Acf1-Flag preparation (see Fig. 4A), these experiments show that full ACF activity can be achieved with the p185 form of Acf1 along with ISWI.

\section{ACF, a chromatin assembly factor that comprises Acf1 and ISWI}

In summary, we have found that the chromatin assembly factor ACF is composed of ISWI and a novel Acf1 subunit. Acf1 contains two PHD fingers, one bromodomain, and two novel conserved regions. Analysis of sequence databases presently reveals one protein, human WSTF which contains each of the conserved sequence motifs in Acf1. acf1 encodes both the p170 and p185 subunits of ACF, and purification of the native form of Acf1 (by assaying for the presence of Acf1 by Western blot analysis) led to the isolation of ACF consisting of Acf1 and ISWI. Furthermore, the Acf1 and ISWI subunits function synergistically in the ATP-dependent assembly of nucleosome arrays.

The finding that Acf1 can significantly increase the activity of the ISWI protein indicates that the proposed motor-like activity of ISWI (as well as related proteins, such as SNF2/SWI2, STH2, Brahma, hSNF2h, hBRM, and BRG1, which are in other chromatin remodeling complexes) can be programmed for specific functions by other components of the remodeling complexes. It is also relevant to note that these results are consistent with the finding that subunits of the human SWI/SNF complex can increase the nucleosome remodeling activity of BRG1 protein, as determined by reduced DNA supercoiling of chromatin and increased ATPase activity (Phelan et al. 1999|

Thus far, three ISWI-containing complexes, termed NURF, CHRAC, and ACF, have been identified in Drosophila, one ISWI (hSNF2h)-containing complex termed RSF (remodeling and spacing factor) has been found in humans (LeRoy et al. 1998), and two complexes termed ISW1 and ISW2, which each contain a distinct ISWI-related protein, have been purified from $S$. cerevisiae
(Tsukiyama et al. 1999). It seems likely that some of the non-ISWI subunits in NURF, CHRAC, RSF, and the ISW1 and ISW2 complexes in yeast will similarly confer additional functionality to the ISWI motor in a manner analogous to Acf1. In the future, it will be interesting to investigate the nature of Acf1 function, as well as to compare the properties of Acf1 with those of related proteins in other chromatin remodeling complexes.

\section{Materials and methods}

Isolation of acf1 cDNA

Native ACF was purified from Drosophila embryos to $>80 \%$ homogeneity by the method of Ito et al. (1997b). The protein was subjected to electrophoresis on an $8 \%$ polyacrylamide-SDS gel and stained with Coomassie brilliant blue G. The p170 and p185 bands were excised, and the polypeptides were digested with Achromobacter protease I (lysylendopeptidase; Wako Chemicals). The resulting peptides were purified by HPLC with a Vydac C18 column and sequenced with an automated protein sequencer (Applied Biosystems). A cDNA fragment was obtained by RT-PCR with oligonucleotides that correspond to the coding sequences of the $\mathrm{p} 170 / \mathrm{p} 185$ peptides, which are depicted in Figure 1A. This partial cDNA segment was used to screen a Drosophila embryo (embryos collected from 0 to $4 \mathrm{hr}$ after egg deposition) cDNA library, and 20 independent cDNAs were obtained. The acf1 cDNA fragment that contains the complete coding sequence was constructed from two overlapping cDNAs.

Northern blot analysis with poly $(\mathrm{A})^{+}$RNA from Drosophila embryos revealed a single band of $\sim 4.5 \mathrm{~kb}$ (data not shown), which corresponds well with the length of the cDNA $(4.8 \mathrm{~kb})$. Southern blot analysis indicated that Acf1 is encoded by a single gene (data not shown). By in situ hybridization to Drosophila polytene chromosomes, the acf1 locus was mapped to region 100E1-2 (T. Laverty, unpubl.).

\section{Antibodies and recombinant constructs}

Polyclonal antibodies against Acf1 were generated by immunization of rabbits with two peptides [acetyl-CTYEEAVKSERAARKK-amide (TYE peptide; amino acid residues 66-80) and acetyl-CAKLIELEKQKAEKKA-amide (AKL peptide; amino acid residues 292-306)] coupled to keyhole limpet hemocyanin. In the developmental Western blot analysis, affinity-purified antibodies (with the TYE peptide) were used. In addition, polyclonal antibodies against an amino-terminal Acfl peptide [acetylKREGFDLNQKEGKNETFC-amide (KRE peptide; amino acid residues 5-21)] were generated and found to recognize both p 170 and p185 forms of Acf1 (data not shown). Polyclonal antibodies against Drosophila ISWI protein were generated by immunization of rabbits with a peptide (acetyl-CAEFDNKIEADRSRRFDamide; amino acid residues 33-48 of ISWI) coupled to keyhole limpet hemocyanin. These antibodies were affinity purified prior to use in the developmental Western blots. Rabbit polyclonal antibodies against Drosophila topoisomerase II were the kind gift of Dr. T. Hsieh (Duke University Medical Center, Durham, NC). Polyclonal antibodies against Drosophila NAP-1 (Ito et al. 1996) and Drosophila CAF-1 p55 (Tyler et al. 1996) were reported elsewhere. The Drosophila ISWI recombinant baculovirus was kindly provided by Dr. C. Wu (National Institutes of Health) (Corona et al. 1999; Hamiche et al. 1999), and it encodes the full-length ISWI protein with an amino-terminal Flag tag (Sigma). Other recombinant baculoviruses were prepared with the BaculoGold system in conjunction with a 
pVL1393-based baculovirus transfer vector (PharMingen). The Acf1 recombinant baculovirus encodes the full-length Acf1 protein without any extraneous sequences or tags. The Acf1-Flag recombinant baculovirus encodes the full-length Acf1 protein with a carboxy-terminal extension of RGSHHHHHHDYKDDDDK, which includes the Flag peptide.

\section{Chromatin assembly}

Chromatin assembly and micrococcal nuclease digestion analysis were performed essentially as described by Bulger and Kadonaga (1994), Bulger et al. (1995), and Ito et al. (1996. 1997b) by using covalently closed circular plasmid DNA that had been relaxed previously with purified, recombinant Drosophila topoisomerase I. Standard reactions (70 $\mu \mathrm{l}$, final volume) contained relaxed, covalently closed circular DNA $(0.35 \mu \mathrm{g}$; 0.17 pmole of a $3.2-\mathrm{kb}$ plasmid), purified core histones from Drosophila embryos (0.35 $\mu$; 3.3 pmoles of core histone octamers), purified native Drosophila NAP-1 (2.8 $\mu$; 64 pmoles of dNAP-1 polypeptides; native dNAP-1 is multimeric), and purified ACF (as indicated, but typically $\sim 0.066-0.22$ pmole) in a buffered medium containing $10 \mathrm{~mm}$ HEPES $\left(\mathrm{K}^{+}\right)$at $\mathrm{pH}$ 7.6, $50 \mathrm{~mm} \mathrm{KCl}, 5$ $\mathrm{mm} \mathrm{NaCl}, 5 \mathrm{~mm} \mathrm{MgCl}_{2}, 5 \%$ (vol/vol) glycerol, $1 \%$ (wt/vol) polyvinyl alcohol (Sigma P-8136), and $1 \%$ (wt/vol) polyethylene glycol (Sigma P-2139), 3 mM ATP, an ATP regenerating system (30 mM phosphocreatine and $1 \mu \mathrm{g} / \mathrm{ml}$ creatine phosphokinase), and bovine serum albumin (140 ng). All components, except for $\mathrm{ACF}$, ATP regeneration system, $\mathrm{MgCl}_{2}$, and DNA, were combined and preincubated for $30 \mathrm{~min}$ on ice. After this preincubation, the $\mathrm{ACF}$, ATP regeneration system, $\mathrm{MgCl}_{2}$, and DNA were added in succession, and the reaction mixture was incubated at $27^{\circ} \mathrm{C}$ for $3-5 \mathrm{hr}$. Where indicated, one unit of ACF is defined to be the amount of ACF containing 22 fmoles of Acf1 polypeptide and 22 fmoles of ISWI polypeptide. Based on glycerol gradient sedimentation analysis of ACF (Ito et al. 1997b), it appears that a protomer of ACF consists of one Acf1 polypeptide and one ISWI polypeptide. Thus, in a standard reaction with one unit of $\mathrm{ACF}$, the molar ratio of $\mathrm{ACF} /$ core histone octamer is $1: 150$.

Western blot analysis of Drosophila at different stages of development

Approximately $100 \mu \mathrm{l}$ volume of frozen wild-type (Canton-S) Drosophila embryos, larvae, pupae, or adult flies was homogenized in a $1.5-\mathrm{ml}$ microcentrifuge tube with a plastic pestle (Kontes). Then, $100 \mu \mathrm{l}$ of buffer [consisting of $10 \mathrm{~mm}$ Tris- $\mathrm{HCl}$ at pH 7.9, $60 \mathrm{~mm} \mathrm{NaCl}, 10 \mathrm{~mm}$ EDTA, 10\% (vol/vol) glycerol, 2 $\mathrm{mm}$ sodium bisulfite, $2 \mathrm{~mm}$ benzamidine- $\mathrm{HCl}, 0.5 \mathrm{~mm}$ phenylmethylsulfonyl fluoride (PMSF), $10 \mu \mathrm{g} / \mathrm{ml}$ leupeptin, $10 \mu \mathrm{g} / \mathrm{ml}$ aprotinin, and $10 \mu \mathrm{g} / \mathrm{ml}$ pepstatin $\mathrm{A}]$ was added, and homogenization was continued for $30 \mathrm{sec}$ on ice. Insoluble material was pelleted by centrifugation for $10 \mathrm{sec}$ in a microcentrifuge. The supernatants were transferred to a fresh microcentrifuge tube containing an equivalent volume of $2 \times$ SDS-electrophoresis sample buffer, and the resulting samples were boiled for $5 \mathrm{~min}$. Each gel lane contained an approximately equivalent amount of total protein, as determined by the Coomassie protein assay (Pierce) as well as by visual inspection of Coomassie bluestained gels or amido black-stained nitrocellulose filters to which the proteins had been transferred. Western blot analysis was carried out with affinity-purified polyclonal antibodies in conjunction with a horseradish peroxidase-coupled secondary antibody and a chemiluminescence reagent (New England Nuclear).

\section{Purification of native Acf1 from Drosophila embryos}

Native Acf1 was purified from a nuclear extract derived from
Drosophila embryos that were collected from 0 to $12 \mathrm{hr}$ after egg deposition. Fractions were assayed for the presence of Acf1 (p170 and p185) by Western blot analysis with antibodies against Acf1 as well as for ACF activity by using the micrococcal nuclease digestion assay. In a typical preparation of nuclear extract (100-200 grams of embryos), nuclei were prepared as described by Kamakaka and Kadonaga (1994), suspended in 100 $\mathrm{ml}$ of buffer A [ $50 \mathrm{~mm}$ HEPES $\left(\mathrm{K}^{+}\right)$at $\mathrm{pH} 7.6,0.35 \mathrm{M} \mathrm{NaCl}, 10 \%$ (vol/vol) glycerol, $1 \mathrm{~mm}$ DTT, $0.2 \mathrm{~mm}$ PMSF, $1 \mathrm{~mm}$ benzamidine], and then incubated with stirring for $30 \mathrm{~min}$ at $4^{\circ} \mathrm{C}$. This mixture was subjected to centrifugation $(10,000 \mathrm{rpm}$ for $10 \mathrm{~min}$ in a Sorvall GSA rotor), and the supernatant was collected and subjected to additional centrifugation $(28,000 \mathrm{rpm}$ for $1 \mathrm{hr}$ in a Beckman Ti45 rotor). The resulting supernatant was collected (the pellet and upper layer were avoided) to give the crude nuclear extract. The crude nuclear extracts from two preparations were combined and subjected to ammonium sulfate precipitation. The $1.0-2.2 \mathrm{M}$ ammonium sulfate precipitate was dialyzed against buffer B $[15 \mathrm{~mm}$ Tris- $\mathrm{HCl}$ at $\mathrm{pH} 7.5,1 \mathrm{~mm}$ EDTA, 10\% (vol/vol) glycerol, $1 \mathrm{~mm}$ DTT, $0.2 \mathrm{~mm}$ PMSF, $1 \mathrm{~mm}$ benzamidine, $0.01 \%$ (vol/vol) NP-40, $10 \mu \mathrm{M} \mathrm{ZnOAc}$ ] containing no additional salt $(0 \mathrm{M} \mathrm{NaCl}$ buffer $\mathrm{B})$ until the conductivity of the sample was approximately equivalent to that of $0.1 \mathrm{M} \mathrm{NaCl}$ buffer B. The dialyzed ammonium sulfate sample was subjected to centrifugation (8000 $\mathrm{rpm}$ for $10 \mathrm{~min}$ in a GSA rotor), and the supernatant was applied to a SP-Sepharose FF (Pharmacia Biotech) resin [column volume $=140 \mathrm{ml}$; column dimensions $($ diam.$\times$ height $)=2.6 \times 26 \mathrm{~cm}$, flow rate $=3 \mathrm{ml} / \mathrm{min}$, fraction size $=22.8 \mathrm{ml}]$. The sample was applied to the column equilibrated in $0.1 \mathrm{M} \mathrm{NaCl}$ buffer B and washed with $420 \mathrm{ml}$ of this buffer. The $0.1 \mathrm{M} \mathrm{NaCl}$ wash was followed by a linear gradient (1400 ml) from 0.1-1 M NaCl in buffer B. Acfl eluted in the 0.29-0.32 M NaCl-containing fractions. The Acf1-containing fractions were dialyzed against buffer C $\left[10 \mathrm{~mm}\right.$ HEPES $\left(\mathrm{K}^{+}\right)$at $\mathrm{pH} 7.6,1.5 \mathrm{~mm} \mathrm{MgCl}_{2}, 10 \%$ (vol/vol) glycerol, $10 \mu \mathrm{M} \mathrm{ZnOAc,} 1$ mM DTT, $0.2 \mathrm{~mm}$ PMSF, $10 \mathrm{~mm} \beta$-glycerophosphate, $0.01 \%$ (vol/vol) NP-40], containing $0.1 \mathrm{M} \mathrm{NaCl}$. The dialyzed SP-Sepharose fractions were applied directly to a Source 15Q (Pharmacia Biotech) resin [column volume $=5 \mathrm{ml}$; column dimensions $($ diam.$\times$ height $)=1 \times 6.4 \mathrm{~cm}$, flow rate $=3 \mathrm{ml} / \mathrm{min}$, fraction size $=1.25 \mathrm{ml}]$. The sample was applied to the column equilibrated in $0.1 \mathrm{M} \mathrm{NaCl}$ buffer $\mathrm{C}$ and washed with $15 \mathrm{ml}$ of this buffer. The $0.1 \mathrm{M} \mathrm{NaCl}$ wash was followed by a linear gradient (150 ml) from 0.1 to $1 \mathrm{M} \mathrm{NaCl}$ buffer C. Acf1 as well as ACF activity eluted in the $0.32-0.34 \mathrm{M} \mathrm{NaCl}$-containing fractions. The Source 15Q fractions were applied directly to a Bio-Gel HT hydroxyapatite (Bio-Rad) resin [column volume $=0.4 \mathrm{ml}$; column dimensions (diam. $\times$ height $)=0.5 \times 2 \mathrm{~cm}$, flow rate $=0.1$ $\mathrm{ml} / \mathrm{min}$, fraction size $=0.3 \mathrm{ml}$. The sample was applied to the column equilibrated in $0 \mathrm{M}$ potassium phosphate at $\mathrm{pH} 7.0$ (KPi) buffer C (containing no NP-40) and washed with $2 \mathrm{ml}$ of this buffer. This wash was followed sequentially by $2-\mathrm{ml}$ washes with $0.01 \mathrm{M} \mathrm{KPi}$ buffer $\mathrm{C}$ and $0.1 \mathrm{M}$ KPi buffer C. The $0.1 \mathrm{M} \mathrm{KPi}$ buffer $\mathrm{C}$ wash was followed by a linear gradient $(6 \mathrm{ml})$ from 0.1 to $0.5 \mathrm{M} \mathrm{KPi}$ buffer $\mathrm{C}$. Acf1 as well as ACF activity eluted in the 0.2-0.25 M KPi-containing fractions. The ACF containing fractions were dialyzed against buffer $\mathrm{C}$ containing $0.1 \mathrm{M} \mathrm{NaCl}$ [containing $0.01 \%$ (vol/vol) NP-40]. The dialyzed Bio-Gel HT hydroxyapatite fractions were applied directly to a POROS $20 \mathrm{HE} 1$ heparin (PerSeptive Biosystems) resin [column volume $=0.2 \mathrm{ml}$, column dimensions (diam. $\times$ height $)=0.5 \times 1 \mathrm{~cm}$, flow rate $=0.2 \mathrm{ml} / \mathrm{min}$, fraction size $=0.083 \mathrm{ml}$. The sample was applied to the column equilibrated in $0.1 \mathrm{M} \mathrm{NaCl}$ buffer $\mathrm{C}$ and washed with $1 \mathrm{ml}$ of this buffer. This wash was followed by a linear gradient $(4 \mathrm{ml}$ ) from 0.1 to $1 \mathrm{M} \mathrm{NaCl}$ buffer C. Acfl as well as ACF activity eluted in the 0.31 to $0.36 \mathrm{NaCl}$-containing frac- 
tions. The POROS heparin fractions were subjected to $15 \%$ $40 \%$ (vol/vol) glycerol gradient sedimentation in $0.1 \mathrm{M} \mathrm{NaCl}$ buffer C (50,000 rpm; 16 hr; Beckman SW55 rotor). The presence of Acf1 (p170 and p185) as well as assembly activity of each fraction was assayed, and the protein composition was determined by polyacrylamide-SDS gel electrophoresis and silver staining. A typical preparation of native Acf1 begins with 300 grams of Drosophila embryos and yields enough purified ACF for at least 400 standard assembly reactions.

\section{Purification of recombinant ACF}

Log-phase $S$. frugiperda (Sf9) cells were diluted with fresh medium to $1 \times 10^{6} / \mathrm{ml}$ in a spinner flask (400 $\mathrm{ml}$ total) and infected with recombinant Acf1 and/or ISWI baculovirus at an m.o.i. of 5-10. [Alternatively, cells were infected on $150-\mathrm{mm}$ culture plates at $2 \times 10^{7}$ cells/plate.] At $44-46 \mathrm{hr}$ subsequent to infection, the cells were pelleted in a clinical centrifuge and washed once with cold phosphate-buffered saline. The cells were suspended in $8 \mathrm{ml}$ of lysis buffer [20 mM Tris- $\mathrm{HCl}$ at $\mathrm{pH} 7.9,500$ $\mathrm{mm} \mathrm{NaCl}, 4 \mathrm{~mm} \mathrm{MgCl}_{2}, 0.4 \mathrm{~mm}$ EDTA, $2 \mathrm{~mm}$ DTT, $20 \mathrm{~mm}$ $\beta$-glycerophosphate, $20 \%$ (vol/vol) glycerol, $0.4 \mathrm{~mm} \mathrm{PMSF}, 1$ $\mathrm{mm}$ benzamidine- $\mathrm{HCl}, 4 \mu \mathrm{g} / \mathrm{ml}$ leupeptin, $2 \mu \mathrm{g} / \mathrm{ml}$ aprotinin] and then disrupted with a Dounce homogenizer (with an A pestle; 10 strokes, $10 \mathrm{~min}$ on ice, 10 additional strokes, another $10 \mathrm{~min}$ on ice, 5 additional strokes). Insoluble material was pelleted by centrifugation in a Sorvall SS-34 rotor $(11,000 \mathrm{rpm}$ for $10 \mathrm{~min})$. The supernatant was combined with $200 \mu \mathrm{l}$ of FlagM2 resin [Sigma; as a 1:1 (vol/vol) slurry in lysis buffer] and $7 \mathrm{ml}$ of dilution buffer $[20 \mathrm{~mm}$ Tris-HCl, $\mathrm{pH} 7.9,10 \%$ (vol/vol) glycerol, and $0.02 \%$ (vol/vol) NP-40]. The slurry was mixed on a rocking platform for $4 \mathrm{hr}$ at $4^{\circ} \mathrm{C}$ in a $15-\mathrm{ml}$ capped polypropylene tube. The resin was washed four times with $12 \mathrm{ml}$ each of wash buffer [20 mM Tris- $\mathrm{HCl}$ at $\mathrm{pH} 7.9,150 \mathrm{~mm} \mathrm{NaCl}, 2 \mathrm{~mm}$ $\mathrm{MgCl}_{2}, 0.2 \mathrm{~mm}$ EDTA, $1 \mathrm{~mm}$ DTT, $10 \mathrm{~mm} \beta$-glycerophosphate, $15 \%(\mathrm{vol} / \mathrm{vol})$ glycerol, $0.01 \%$ (vol/vol) NP-40, $0.2 \mathrm{mM}$ PMSF, $0.5 \mathrm{~mm}$ benzamidine- $\mathrm{HCl}, 2 \mu \mathrm{g} / \mathrm{ml}$ leupeptin, $1 \mu \mathrm{g} / \mathrm{ml}$ aprotinin]. Then, protein was eluted by four successive cycles of addition and removal of $100 \mu \mathrm{l}$ of elution buffer [wash buffer containing $0.2 \mathrm{mg} / \mathrm{ml}$ Flag peptide (Sigma) and $0.5 \mathrm{mg} / \mathrm{ml}$ recombinant human insulin (Boehringer Mannheim)]. Protein concentrations were estimated by polyacrylamide-SDS gel electrophoresis and staining with Coomassie brilliant blue R-250 along with BSA standards. Typical yields of ACF are $\sim 0.1 \mu \mathrm{g} / \mathrm{ml}$ of suspension culture or $10 \mu \mathrm{g} / 150-\mathrm{mm}$ plate.

\section{Acknowledgments}

We thank Jessica Tyler, Patricia Willy, and Jennifer Butler for critical reading of the manuscript. We are grateful to Carl Wu for the ISWI baculovirus; Todd Laverty for determination of the cytological location of the acf1 gene; Tao Hsieh for antibodies against Drosophila topoisomerase II; and Angel Lee for technical assistance. This work was supported by grants from the National Science Foundation (MCB-9631121) and National Institutes of Health (NIH; GM46995 and GM58272) to J.T.K. R.K. was supported by a grant from the NIH (CA13106).

The publication costs of this article were defrayed in part by payment of page charges. This article must therefore be hereby marked 'advertisement' in accordance with 18 USC section 1734 solely to indicate this fact.

\section{References}

Aasland, R., T.J. Gibson, and A.F. Stewart. 1995. The PHD finger: Implications for chromatin-mediated transcriptional regulation. Trends Biochem. Sci. 20: 56-59.
Adams, C.R. and R.T. Kamakaka. 1999. Chromatin assembly: Biochemical identities and genetic redundancy. Curr. Opin. Genet. Dev. 9: 185-190.

Annunziato, A.T. 1995. Histone acetylation during chromatin replication and nucleosome assembly. In The nucleus, (ed. A.P. Wolffe), Vol. 1, pp. 31-56. JAI Press; Greenwich, CT.

Bellugi, U., A. Bihrle, T. Jernigan, D. Trauner, and S. Doherty. 1990. Neuropsychological, neurological, and neuroanatomical profile of Williams syndrome. Am. I. Hum. Genet. (Suppl.) 6: 115-125.

Bulger, M. and J.T. Kadonaga. 1994. Biochemical reconstitution of chromatin with physiological nucleosome spacing. Methods Mol. Genet. 5: 241-262.

Bulger, M., T. Ito, R.T. Kamakaka, and J.T. Kadonaga. 1995. Assembly of regularly-spaced nucleosome arrays by dCAF-1 and a $56 \mathrm{kDa}$ histone-binding protein. Proc. Natl. Acad. Sci. 92: $11726-11730$

Cairns, B.R. 1998. Chromatin remodeling machines: Similar motors, ulterior motives. Trends Biochem. Sci. 23: 20-25.

Corona, D.F.V., G. Längst, C.R. Clapier, E.J. Bonte, S. Ferrari, J.W. Tamkun, and P.B. Becker. 1999. ISWI is an ATP-dependent nucleosome remodeling factor. Mol. Cell 3: 239245.

Elfring, L.K., R. Deuring, C.M. McCallum, C.L. Peterson, and J.W. Tamkun. 1994. Identification and characterization of Drosophila relatives of the yeast transcriptional activator SNF2/SWI2. Mol. Cell. Biol. 14: 2225-2234.

Ewart, A.K., C.A. Morris, D. Atkinson, W. Jin, K. Sternes, P. Spallone, A.D. Stock, M. Leppert, and M.T. Keating. 1993. Hemizygosity at the elastin locus in a developmental disorder, Williams syndrome. Nat. Genet. 5: 11-16.

Gdula, D.A., R. Sandaltzopoulos, T. Tsukiyama, V. Ossipow, and C. Wu. 1998. Inorganic pyrophosphatase is a component of the Drosophila nucleosome remodeling factor complex. Genes \& Dev. 12: 3206-3216.

Glikin, G.C., I. Ruberti, and A. Worcel. 1984. Chromatin assembly in Xenopus oocytes: In vitro studies. Cell 37: 33-41.

Grunstein, M. 1997. Histone acetylation in chromatin structure and transcription. Nature 389: 349-352.

Hamiche, A., R. Sandaltzopoulos, D.A. Gdula, and C. Wu. 1999. ATP-dependent histone octamer sliding mediated by the chromatin remodeling complex NURF. Cell (in press).

Haynes, S.R., C. Dollard, F. Winston, S. Beck, J. Trowsdale, and I.B. Dawid. 1992. The bromodomain: A conserved sequence found in human, Drosophila, and yeast proteins. Nucleic Acids Res. 20: 2603.

Hung, M.-C. and P.C. Wensink. 1983. Sequence and structure conservation in yolk proteins and their genes. J. Mol. Biol. 164: 481-492.

Ito, T., M. Bulger, R. Kobayashi, and J.T. Kadonaga. 1996. Drosophila NAP-1 is a core histone chaperone that functions in ATP-facilitated assembly of regularly-spaced nucleosomal arrays. Mol. Cell. Biol. 16: 3112-3124.

Ito, T., J.K. Tyler, and J.T. Kadonaga. 1997a. Chromatin assembly factors: A dual function in nucleosome formation and mobilization? Genes Cells 2: 593-600.

Ito, T., M. Bulger, M.J. Pazin, R. Kobayashi, and J.T. Kadonaga. 1997b. ACF, an ISWI-containing and ATP-utilizing chromatin assembly and remodeling factor. Cell 90: 145-155.

Jansa, P., S.W. Mason, U. Hoffmann-Rohrer, and I. Grummt. 1998. Cloning and functional characterization of PTRF, a novel protein which induces dissociation of paused ternary transcription complexes. EMBO J. 17: 2855-2864.

Jeanmougin, F., J.-M. Wurtz, B. Le Douarin, P. Chambon, and R. Losson. 1997. The bromodomain revisited. Trends Biochem. Sci. 22: 151-153. 
Kadonaga, J.T. 1998. Eukaryotic transcription: An interlaced network of transcription factors and chromatin-modifying machines. Cell 92: 307-313.

Kamakaka, R.T. and J.T. Kadonaga. 1994. The soluble nuclear fraction, a highly efficient transcription extract from Drosophila embryos. Methods Cell Biol. 44: 225-235.

Kaufman, P.D. 1996. Nucleosome assembly: The CAF and the HAT. Curr. Opin. Cell Biol. 8: 369-373.

Kornberg, R.D. and Y. Lorch. 1999. Chromatin-modifying and -remodeling complexes. Curr. Opin. Genet. Dev. 9: 148-151.

LeRoy, G., G. Orphanides, W.S. Lane, and D. Reinberg. 1998. Requirement of RSF and FACT for transcription of chromatin templates in vitro. Science 282: 1900-1904.

Lu, X., X. Meng, C.A. Morris, and M.T. Keating. 1998. A novel human gene, WSTF, is deleted in Williams syndrome. Genomics 54: 241-249.

Martínez-Balbás, M.A., T. Tsukiyama, D. Gdula, and C. Wu. 1998. Drosophila NURF-55, a WD repeat protein involved in histone metabolism. Proc. Natl. Acad. Sci. 95: 132-137.

Morris, C.A., S.A. Demsey, C.O. Leonard, C. Dilts, and B.L. Blackburn. 1988. Natural history of Williams syndrome: Physical characteristics. J. Pediatr. 113: 318-326.

Nagase, T., K. Ishikawa, D. Nakajima, M. Ohira, N. Seki, N. Miyajima, A. Tanaka, H. Kotani, N. Nomura, and O. Ohara. 1997. Prediction of the coding sequences of unidentified human genes. VII. The complete sequences of 100 new cDNA clones from brain which can code for large proteins in vitro. DNA Res. 4: 141-150.

Phelan, M.L., S. Sif, G.J. Narlikar, and R.E. Kingston. 1999. Reconstitution of a core chromatin remodeling complex from SWI/SNF subunits. Mol. Cell 3: 247-253.

Pollard, K.J. and C.L. Peterson. 1998. Chromatin remodeling: A marriage between two families? BioEssays 20: 771-780.

Roth, S.Y. and C.D. Allis. 1996. Histone acetylation and chromatin assembly: A single escort, multiple dances? Cell 87: 5-8.

Schindler, U., H. Beckmann, and A.R. Cashmore. 1993. HAT3.1, a novel Arabidopsis homeodomain protein containing a conserved cysteine-rich region. Plant I. 4: 137150.

Tate, P., M. Lee, S. Tweedie, W.C. Skarnes, and W.A. Bickmore. 1998. Capturing novel mouse genes encoding chromosomal and other nuclear proteins. J. Cell Sci. 111: 2575-2585.

Tsukiyama, T. and C. Wu. 1995. Purification and properties of an ATP-dependent nucleosome remodelling factor. Cell 83: $1011-1020$.

- 1997. Chromatin remodeling and transcription. Curr. Opin. Genet. Dev. 7: 182-191.

Tsukiyama, T., C. Daniel, J. Tamkun, and C. Wu. 1995. ISWI, a member of the SWI2/SNF2 ATPase family, encodes the 140 $\mathrm{kDa}$ subunit of the nucleosome remodelling factor. Cell 83: $1021-1026$.

Tsukiyama, T., J. Palmer, C.C. Landel, J. Shiloach, and C. Wu. 1999. Characterization of the Imitation Switch subfamily of ATP-dependent chromatin-remodeling factors in Saccharomyces cerevisiae. Genes \& Dev. 13: 686-697.

Tyler, J.K., M. Bulger, R.T. Kamakaka, R. Kobayashi, and J.T. Kadonaga. 1996. The p55 subunit of Drosophila chromatin assembly factor 1 is homologous to a histone deacetylaseassociated protein. Mol. Cell. Biol. 16: 6149-6159.

Varga-Weisz, P.D., M. Wilm, E. Bonte, K. Dumas, M. Mann, and P.B. Becker. 1997. Chromatin-remodelling factor CHRAC contains the ATPases ISWI and topoisomerase II. Nature 388: 598-602.

Wolffe, A.P. 1995. Chromatin: structure and function, 2nd ed. Academic Press, San Diego, CA.
Workman, J.L. and R.E. Kingston. 1998. Alteration of nucleosome structure as a mechanism of transcriptional regulation. Annu. Rev. Biochem. 67: 545-579.

Wu, C. 1997. Chromatin remodeling and the control of gene expression. J. Biol. Chem. 272: 28171-28174. 


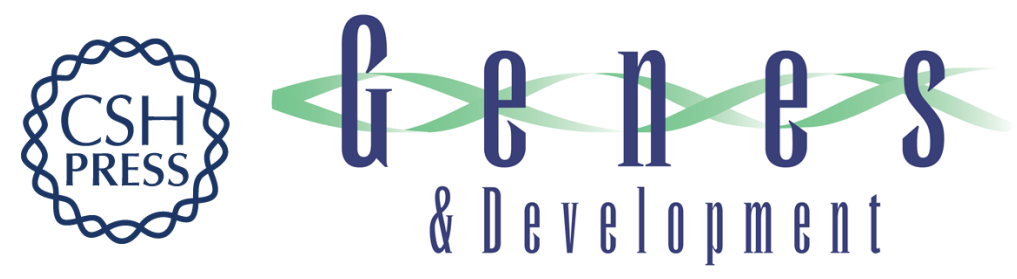

\section{ACF consists of two subunits, Acf1 and ISWI, that function cooperatively in the ATP-dependent catalysis of chromatin assembly}

Takashi Ito, Mark E. Levenstein, Dmitry V. Fyodorov, et al.

Genes Dev. 1999, 13:

References This article cites 39 articles, 11 of which can be accessed free at:

http://genesdev.cshlp.org/content/13/12/1529.full.html\#ref-list-1

License

Email Alerting
Service $\begin{aligned} & \text { Receive free email alerts when new articles cite this article - sign up in the box at the top } \\ & \text { right corner of the article or click here. }\end{aligned}$

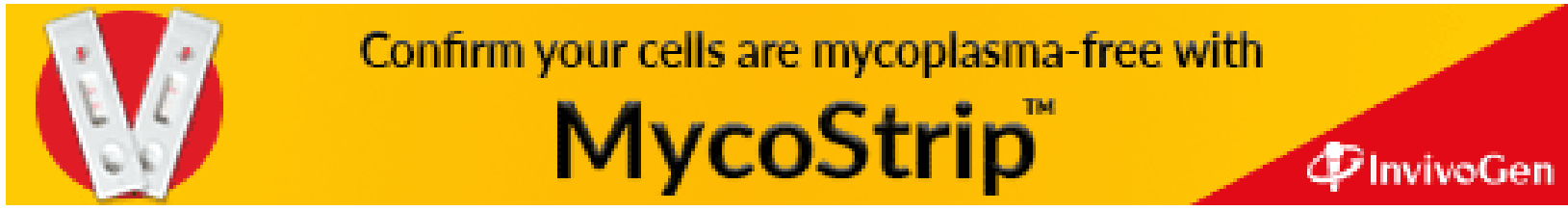

